SHORT COMMUNICATION

\title{
An in vitro study on the interaction between ethanol and imipramine at their high concentrations using human liver microsomes
}

\section{Einosuke Tanaka •Takako Nakamura • Masaru Terada • Katsuya Honda}

Received : 14 June 2007/ Accepted : August 2007

(C) Japanese Association of Forensic Toxicology and Springer 2007

E. Tanaka (corresponding author) • T. Nakamura $\bullet$ K. Honda

Department of Legal Medicine ,Institute of Community Medicine, University of Tsukuba, Ibaraki-ken 305-8575, Japan

e-mail: einosuke@md.tsukuba.ac.jp

\section{Terada}

Department of Legal Medicine, School of Medicine, Toho University, 5-21-16 Omorinishi, Otaku Tokyo 143-8540, Japan 


\begin{abstract}
Imipramine is a tricyclic antidepressant widely used for the treatments of major depression, while ethanol is one of most joyful beverages for mankind. Sometimes, toxic interactions occur following combined administration of these two compounds. In this study, we have investigated the in vitro interaction between ethanol and imipramine at their high concentrations by observing a mixed-function oxidation reaction using human liver microsomes. Imipramine and its three main metabolites (desipramine, 2-hydroxyimipramine $=2$-OHI and 2-hydroxydesipramine $=2$-OHD) were measured by high-performance liquid chromatography with ultraviolet detection. As results, the production of 2-OHD, the main metabolite of imipramine, was significantly inhibited by $15-50 \%(\mathrm{p}<0.05)$ by ethanol, but that of desipramine or $2-\mathrm{OHI}$ was not. These results suggest that enhanced toxicity is attained by simultaneous administration of ethanol and high-dose imipramine in actual human body.
\end{abstract}

Keywords Drug interaction - Cytochrome P450 - Ethanol • Imipramine • In vitro experiments $\bullet$ Synergism 


\section{Introduction}

The majority of serious cases of drug-drug interactions of toxicological and clinical interest appear attributable to pharmacokinetic phenomena. These are usually due to alterations in hepatic drug metabolic pathways catalyzed by the cytochrome P450 (CYP) system. The adverse effects can result from inhibition or induction of metabolic enzymes; the inhibition appearing is more important in many poisoning cases.

Imipramine is mainly metabolized by CYP2D6 [1] and it is the prototype of all tricyclic antidepressant drugs for the treatments of major depression. Adverse reactions to imipramine therapy include orthostatic hypotension, paresthesias, dry mouth, blurred vision, confusion, disorientation, insomnia, agranulocytosis and paralytic ileus. Its toxicity is characterized by hyperactivity, seizers, respiratory depression, hypertension, cardiac arrhythmias, hyperpyrexia, tachycardia, urinary retention, coma, circulatory collapse and death.

Ethanol can affect the pharmacokinetics of drugs by altering gastric emptying or liver metabolism (by inducing CYP2E1). Drugs may conversely affect the pharmacokinetics of ethanol by altering gastric emptying and inhibiting ethanol dehydrogenase (ADH). Long-term intake of large amounts of ethanol induces pathways of metabolism which are independent of $\mathrm{ADH}$ [2-4]. Other enzymes, especially the microsomal ethanol-oxidizing (MEOS) system, including CYP2E1, are also involved at higher doses of ethanol, and these metabolize up to $10 \%$ of the ingested ethanol $[3,5,6]$. After chronic ethanol consumption, there is 4- to 10-fold induction of CYP2E1 [6]. Ethanol metabolism by this enzyme results in the generation of acetaldehyde and oxygen radicals. The induction of CYP2E1 may cause increased metabolism of other xenobiotics to toxic metabolites by this enzyme [7].

We have already described the toxicological interactions between ethanol and three benzodiazepines (triazolam [8], flunitrazepam [9] and alprazolam [10]). Fatal poisoning 
involving coadministration of alcohol and benzodiazepines, especially these three drugs continues to be a serious social problem.

In this study we have investigated the in vitro interaction between ethanol and imipramine by monitoring and its three main metabolites (desipramine, 2-hydroxyimipramine $=2$-OHI, and 2-hydroxydesipramine $=2$-OHD) at high-dose concentrations using human liver microsomes.

\section{Materials and methods}

Materials

NADPH was purchased from Oriental Yeast (Tokyo, Japan). Clomipramine (internal standard, IS) and ethanol were purchased from Sigma (St. Louis, MO, USA) and Wako (Osaka, Japan), respectively. Imipramine and its three metabolites (desipramine, 2-OHI and 2-OHD) were kindly provided by Mitsubishi Pharma (Osaka, Japan). All other chemicals and reagents used were of the highest quality commercially available.

Microsomes from three pooled human livers (catalog Nos : H003, H013 and H032) containing representative activities of CYP1A2, CYP2A6, CYP2B6, CYP2C9, CYP2C19, CYP2D6, CYP2E1 and CYP3A4 were obtained from Daiichi Pure Chemical (Tokyo, Japan).

Enzyme assay

The incubation mixture contained enzyme protein $(0.125 \mathrm{mg}), 0.1 \mathrm{M}$ potassium phosphate buffer ( $\mathrm{pH}$ 7.4), $0.1 \mathrm{mM} \mathrm{NADPH}$, imipramine (substrate concentration : $0-10 \mu \mathrm{M}$; 
therapeutic level 0.155-0.465 $\mu \mathrm{M}$, toxic level 3.27 $\mu \mathrm{M}$ and fatal level 4.74-6.33 $\mu \mathrm{M}$ ) [5] and ethanol (0-80 mM; toxic level 20-40 $\mathrm{mM}$ and fatal level 70-80 $\mathrm{mM})$ in a total volume of 0.5 $\mathrm{ml}$. Incubations were initiated following a $3-$ min preincubation at $37^{\circ} \mathrm{C}$ by the addition of NADPH and generally carried out for $20 \mathrm{~min}$ in a shaking water-bath at $37^{\circ} \mathrm{C}$. The reaction was terminated by adding $100 \mu \mathrm{l}$ acetonitrile and $3 \mathrm{ml}$ tert-butyl methyl ether containing 9.5 $\mu \mathrm{g} / \mathrm{ml}$ clomipramine (IS). After vortex mixing for $5 \mathrm{~min}$, the tubes were centrifuged at 1,200 $\mathrm{g}$ for $3 \mathrm{~min}$. The organic phase was transferred to a clean conical tube and evaporated in a water-bath at about $40^{\circ} \mathrm{C}$ under a gentle stream of nitrogen. The residue was dissolved in $200 \mu 1$ mobile phase and $50 \mu 1$ injected into the HPLC system.

Determination of imipramine metabolites

The HPLC equipment consisted of a pump (Model CCPS, Tosho, Tokyo, Japan) and a variable-wavelength UV detector (Model UV-8020, Tosho, Tokyo, Japan). Separation was achieved using a $\mathrm{C}_{18}$ reversed-phase column (150 mm X $4.6 \mathrm{~mm}$ I.D., particle size $3 \mu \mathrm{m}$, Inertsil ODS-3, GL Sciences, Tokyo, Japan). The mobile phase was $50 \mathrm{mM}$ $\mathrm{K}_{2} \mathrm{HPO}_{4} / \mathrm{methanol} /$ acetonitrile $(50: 10: 40, \mathrm{v} / \mathrm{v} / \mathrm{v})$ and the flow rate was $0.7 \mathrm{ml} / \mathrm{min}$. The absorbance of the eluent was monitored at $254 \mathrm{~nm}$. All instruments were operated at ambient laboratory temperature (ca. $23^{\circ} \mathrm{C}$ ). The retention times of 2-OHD, 2-OHI, desipramine and IS in a spiked sample of human liver microsomes was 3.2, 3.8, 6.3 and 16.2 min, respectively. The limits of detection (LOD) of desipramine, 2-OHI and 2-OHD were 20, 25 and $10 \mathrm{nM}$, respectively. The intra- and inter-assay coefficients of variation (C.V.) for the three metabolites were less than $5 \%$. 
Statistical analysis

To determine significant differences between group mean values, data were subjected to a one-way ANOVA test for repeated measures. Differences were considered significant at $p<0.05$. Results are expressed as means \pm SE.

\section{Results and discussion}

Table 1 shows in vitro production rates for imipramine metabolites desipramine, 2-OHI and 2-OHD according to various concentrations of ethanol and imipramine. Only the production of 2-OHD, the main metabolite of imipramine, was significantly inhibited by $15-50 \%$ by ethanol, but that of desipramine and 2-OHI was not. This inhibition was not dependent on ethanol concentrations tested.

Koyama et al. [1] reported that the metabolism of imipramine was most efficiently catalyzed by CYP2D6, followed by CYP1A2 and CYP2C19 in a recombinant human CYP isoform study. However, it is not known which isozyme(s) is responsible for the interaction between imipramine and ethanol at the present time.

Some reports for the in vitro experiments on the interaction between ethanol and drugs through CYP isozymes should be mentioned. Rubin et al. [11] reported that, ethanol $(10,50$ and $100 \mathrm{mM}$ ) in vitro inhibited the activities of aniline (competitive) and pentobarbital (mixed type) hydroxylases, and the demethylation of aminopyrene (competitive) and ethylmorphine (mixed type). Schuppel and Kuthe [12] also studied the in vi tro inhibition by ethanol of microsomal hydroxylation for a series of barbiturates (amobarbital, cyclobarbital and pentbarbital : mixed type), but hexobarbital hydroxylation remains 
unaffected by ethanol $(210 \mathrm{mM})$. In contrast, Cinti et al. [13] reported that, using liver slices, $N$-demethylation of aminopyrine was stimulated by $35-40 \%$ at a low ethanol concentration (2 $\mathrm{mM})$, whereas no stimulation occurred at a high concentration $(100 \mathrm{mM})$.

In conclusion, our results using a human liver microsomal preparation have showed that the formation of the 2-OHD metabolite of imipramine is inhibited by ethanol. To our knowledge, this kind of studies has not been reported. Therefore, enhanced toxicity may be attained by simultaneous administration of high-dose ethanol and imipramine in a human body.

In the near future, the specific CYP isozyme(s), which is responsible for interaction between ethanol and imipramine, should be identified; such a study will be useful for assessing the enhanced toxicity when both compounds are ingested simultaneously in forensic and clinical toxicology. 


\section{References}

1. Koyama E, Chiba K, Tani M, Ishizaki T (1997) Reappraisal of human CYP isoforms involved in imipramine N-demethylation and 2-hydroxylation: a study using microsomes obtained from putative extensive and poor metabolizers of S-mephenytoin and eleven recombinant human CYPs. J Pharmacol Exp Ther 281:1199-1210

2. Lieber CS (1994) Mechanisms of ethanol-drug-nutrition interactions. J Toxicol Clin Toxicol 32:631-681

3. Lieber CS (1994) Susceptibility to alcohol-related liver injury. Alcohol Alcohol Suppl 2:315-326

4. Kitson KE (1996) Ethanol and acetaldehyde metabolism: past, present. and future. Alcohol Clin Exp Res 20 (Suppl 8):82A-92A

5. Asai H, Imaoka S (1996) Microsomal ethanol oxidizing system activity by human hepatic cytochrome P450's. J Pharmacol Exp Ther 277: 1004-1009

6. Song BJ (1996) Ethanol-inducible cytochrome P450 (CYP2E1): biochemistry, molecular biology and clinical relevance: 1996 up-date. Alcohol Clin Exp Res 20 (Suppl 8): 138A-146A

7. Lieber CS (1997) Ethanol metabolism, cirrhosis and alcoholism. Clin Chim Acta 257:59-84

8. Tanaka E, Nakamura T, Terada M, Shinozuka T, Honda K (2005) A study of the in vitro interaction between ethanol, and triazolam and its two metabolites using human liver microsomes. J Clin Forensic Med 12:245-248

9. Tanaka E, Nakamura T, Terada M, Shinozuka T, Honda K (2005) Preliminary study of the in vitro interaction between alcohol, high-dose flunitrazepam and its three metabolites using human liver microsomes. Basic Clin Pharmacol Toxicol 96:88-90

10. Tanaka E, Nakamura T, Terada M, Shinozuka T, Honda K (2007) Metabolic interaction between ethanol, high-dose alprazolam and its two main metabolites using human liver microsomes in vitro. J Forensic Legal Med 14:348-351

11. Rubin E, Gang H, Misra PS, Lieber CS (1970) Inhibition of drug metabolism by acute ethanol intoxication. A hepatic microsomal mechanism. Am J Med 49:801-816

12. Schuppel RV, Kuthe C (1980) Ethanol as a selective inhibitor of microsomal barbiturate hydroxylation in vitro and in vivo. Adv Exp Med Biol 132:363-372

13. Cinti DL, Grundin R, Orrenius S (1973) The effect of ethanol on drug oxidations in vitro and the significance of ethanol-cytochrome P-450 interaction. Biochem $\mathrm{J}$ $134: 367-375$ 
Table 1 Effect of ethanol on in vitro production of imipramine metabolites by human liver microsomes

\begin{tabular}{|c|c|c|c|c|}
\hline & \multicolumn{4}{|c|}{ Metabolite production rate $(\mu \mathrm{mol} / \mathrm{min} / \mathrm{mg} \text { protein })^{\mathrm{a}}$} \\
\hline & \multirow[b]{2}{*}{$0 \mathrm{mM}$ (control) $(\%)$} & \multicolumn{2}{|c|}{ Ethanol concntrations } & \multirow[b]{2}{*}{$80 \mathrm{mM}(\%)$} \\
\hline & & $20 \mathrm{mM}(\%)$ & $40 \mathrm{mM}(\%)$ & \\
\hline \multicolumn{5}{|c|}{ Imipramine $(2 \mu \mathrm{M})$} \\
\hline Desipramine & $0.08 \pm 0.036(100)$ & $0.05 \pm 0.010(63)$ & $0.06 \pm 0.015(75)$ & $0.08 \pm 0.025(100)$ \\
\hline 2-OHI & $0.27 \pm 0.019(100)$ & $0.34 \pm 0.022(125)$ & $0.33 \pm 0.025(122)$ & $0.31 \pm 0.028(114)$ \\
\hline 2-OHD & $0.02 \pm 0.002(100)$ & $0.01 \pm 0.002(50)$ & $0.04 \pm 0.018(200)$ & $0.02 \pm 0.003(100)$ \\
\hline \multicolumn{5}{|c|}{ Imipramine $(4 \mu \mathrm{M})$} \\
\hline Desipramine & $0.18 \pm 0.047(100)$ & $0.12 \pm 0.014(66)$ & $0.11 \pm 0.012(61)$ & $0.15 \pm 0.037(83)$ \\
\hline 2-OHI & $0.54 \pm 0.029(100)$ & $0.44 \pm 0.036(81)$ & $0.44 \pm 0.015(81)$ & $0.44 \pm 0.052(81)$ \\
\hline 2-OHD & $0.03 \pm 0.001(100)$ & $0.04 \pm 0.005(133)$ & $0.03 \pm 0.004(100)$ & $0.04 \pm 0.016(133)$ \\
\hline \multicolumn{5}{|c|}{ Imipramine $(6 \mu \mathrm{M})$} \\
\hline Desipramine & $0.24 \pm 0.038(100)$ & $0.19 \pm 0.016(79)$ & $0.18 \pm 0.017(75)$ & $0.22 \pm 0.032(91)$ \\
\hline 2-OHI & $0.65 \pm 0.102(100)$ & $0.56 \pm 0.019(86)$ & $0.52 \pm 0.044(80)$ & $0.61 \pm 0.052(93)$ \\
\hline 2-OHD & $0.07 \pm 0.009(100)$ & $0.05 \pm 0.005(71) *$ & $0.06 \pm 0.008(85) *$ & $0.05 \pm 0.032(71) *$ \\
\hline \multicolumn{5}{|c|}{ Imipramine $(8 \mu \mathrm{M})$} \\
\hline Desipramine & $0.29 \pm 0.038(100)$ & $0.26 \pm 0.013(89)$ & $0.26 \pm 0.056(89)$ & $0.25 \pm 0.054(86)$ \\
\hline 2-OHI & $0.69 \pm 0.151(100)$ & $0.61 \pm 0.021(88)$ & $0.61 \pm 0.034(88)$ & $0.63 \pm 0.079(91)$ \\
\hline 2-OHD & $0.10 \pm 0.003(100)$ & $0.05 \pm 0.002(50) *$ & $0.06 \pm 0.002(60) *$ & $0.07 \pm 0.002(70) *$ \\
\hline \multicolumn{5}{|c|}{ Imipramine $(10 \mu \mathrm{M})$} \\
\hline Desipramine & $0.31 \pm 0.021$ & $0.30 \pm 0.13(96)$ & $0.31 \pm 0.028(100)$ & $0.31 \pm 0.023(100)$ \\
\hline 2-OHI & $0.78 \pm 0.108(100)$ & $0.66 \pm 0.022(84)$ & $0.70 \pm 0.067$ (89) & $0.64 \pm 0.080(82)$ \\
\hline 2-OHD & $0.13 \pm 0.018(100)$ & $0.07 \pm 0.006(53) *$ & $0.08 \pm 0.008(61) *$ & $0.07 \pm 0.003(53) *$ \\
\hline
\end{tabular}

${ }^{\mathrm{a}}$ Each values are the mean $\pm \mathrm{SE}$ of triplicate determinations. 2-OHI $=$ 2-hydroxyimipramine, 2-OHD $=2$-hydroxydesipramine, $*=\mathrm{p}<0.05$ (vs control) 